\title{
A percepção dos idosos sobre o saber biomédico no cuidado à velhice e às "coisas da idade"
}

\author{
I 1 Gustavo Vaz de Oliveira Moraes, ${ }^{2}$ Karla Giacomin, \\ ${ }^{3}$ Wagner Jorge Santos, ${ }^{4}$ Josélia Oliveira Araujo Firmo I
}

Resumo: O saber biomédico tem influência sobre as práticas objetivas e subjetivas das pessoas em relação ao corpo, à saúde e à vida. Diante do contexto de envelhecimento populacional, a pesquisa de cunho antropológico objetiva compreender como os elementos do saber biomédico influenciam a percepção do processo saúde-doença-envelhecimento entre idosos residentes na comunidade de Bambuí, Minas Gerais. O estudo incluiu 57 idosos (27 homens e 30 mulheres) com idades entre 62 e 96 anos. O modelo dos signos, significados e ações guiou a coleta e análise dos dados, permitindo a sistematização dos elementos do contexto que participam da construção de maneiras típicas de pensar e agir dos entrevistados diante do envelhecimento. Os resultados demonstram que o conhecimento médico-científico apropriado pela cultura local influencia os modos de pensar e agir dos idosos investigados. Foram identificadas como categorias analíticas de significados: a valorização da biomedicina, a culpabilização dos indivíduos, a naturalização das doenças na velhice e os recursos e ações utilizados pelos idosos. Os participantes reproduzem a visão biomédica que associa as doenças e limitaçôes à idade, responsabilizam os próprios idosos pela atual condição de saúde e ainda recomendam repouso e resignação diante da velhicedoença vivida com incapacidade.

Palavras-chave: idoso; saber biomédico; envelhecimento; processo saúde-doença.

\author{
${ }^{1}$ Centro de Pesquisas \\ René Rachou/Fiocruz. \\ Belo Horizonte-MG, Brasil \\ (gvomoraes@hotmail.com). \\ ${ }^{2}$ Centro de Pesquisas \\ René Rachou/Fiocruz. \\ Belo Horizonte-MG, Brasil \\ (kcgiacomin@hotmail.com). \\ ${ }^{3}$ Centro de Pesquisas René \\ Rachou/Fiocruz. Belo Horizonte- \\ MG, Brasil (wagnerjorge@cpqrr. \\ fiocruz.br). \\ ${ }^{4}$ Centro de Pesquisas \\ René Rachou/Fiocruz. Belo \\ Horizonte-MG, Brasil (firmoj@ \\ cpqrr.fiocruz.br).
}

Recebido em: 31/12/2014

Aprovado em: 28/06/2015 
A ciência biomédica contemporânea existe há quase três séculos e responde pelo atual modelo hegemônico do corpo humano (TESSER; LUZ, 2002), cujas raízes se encontram no paradigma biomecânico positivista. Desde o século XIX, essa ciência produz um discurso com forte determinação biológica a respeito da saúde e da doença, estabelecendo novas relações de causa e efeito para as moléstias. Além disso, fazendo analogia a uma máquina, ela analisa o corpo humano de forma objetiva, peça a peça (RIOS et al., 2007), mas, ao fazê-lo, leva à transformação desse corpo em objeto, e, consequentemente, à perda da identidade do sujeito, quando paciente (MOULIN, 2009).

No último século, fortalecido pelo recuo das epidemias e pelo aumento da expectativa de vida, o saber biomédico vem se tornando uma espécie de "porta-voz" oficial do corpo humano na sociedade ocidental ou de "verdade universal do corpo" (LE BRETON, 2011), apropriando-se de etapas naturais da vida, como o nascimento, o envelhecimento e a morte. Assim, esse saber passa a estabelecer normas de conduta sobre os modos de vida do ser humano e a produzir conceitos, diagnósticos e intervenções para classificar o que seria normal ou patológico (CONRAD, 2007).

Progressivamente, também se observam sua superfragmentação em especialidades e a transformação da consulta médica em um "negócio de especialistas", no qual o paciente, visto de forma fragmentada, não dispõe de nenhuma autonomia relativa ao seu processo de saúde-doença e à escolha do método propedêutico e/ou terapêutico. Dessa maneira, a prática biomédica institui uma normatização vertical, pela qual o médico detém o conhecimento, de forma prescritiva, autoritária e dotada de uma visão restrita e curativa das doenças (GADAMER, 2006). Mais recentemente, o envelhecimento populacional introduz uma mudança no perfil epidemiológico, no qual predominam doenças crônicas não transmissíveis e comorbidades que demandam cuidados continuados, podendo levar uma pessoa idosa a consultar muitos especialistas, para, ao final, permanecer desamparada e sem cuidado (LE BRETON, 2011).

Diante do exposto, o objetivo deste estudo é compreender como o saber biomédico apreendido pela pessoa idosa interfere nas práticas de saúde e influencia o modo de pensar e agir dos indivíduos face ao processo saúdedoença-envelhecimento. 
Esta pesquisa integra um projeto maior, intitulado "Abordagem Antropológica da Dinâmica da Funcionalidade em Idosos", aprovado pelo Comitê de Ética em pesquisa com seres humanos do Centro de Pesquisa René Rachou (CAAE 0028.0.245.000-09). Todos os participantes assinaram um termo de consentimento, em acordo com a Resolução CNS/Conep no466/2012. A pesquisa foi desenvolvida na perspectiva da abordagem qualitativa, de cunho antropológico, tendo utilizado o método de coleta de dados baseado no contato direto intersubjetivo entre o pesquisador e seu objeto no ambiente natural do sujeito, o qual constitui espaço inequívoco para a observação sem controle ou a modificação das variáveis (TURATO, 2005).

$\mathrm{O}$ estudo foi conduzido na área urbana da cidade de Bambuí, município do Centro-Oeste de Minas Gerais, distante 270 quilômetros da capital Belo Horizonte, com população total estimada em 2010 de 23 mil habitantes, incluindo zonas rural e urbana (IBGE). A principal fonte de renda do município é a exploração produtiva de seus recursos naturais, em atividades agropecuárias e de extração mineral (RIOS et al., 2011). À semelhança do observado no Brasil, após 1950 a população local experimenta: a) intensa urbanização, tendo o contingente urbano passado de $16 \%$ em 1950 para $85 \%$ da população total do município em 2010; e b) franco envelhecimento: em 1960, menos de 4\% dos habitantes tinham 60 ou mais anos de idade; em 2010, esse grupo etário quadruplicou, em um ritmo de envelhecimento superior ao nacional (IBGE, 2010).

Quanto às questões relativas aos serviços de saúde, a cidade se destacou como centro de profilaxia contra a doença de Chagas, sendo que o Posto Avançado de Estudos Emanuel Dias, criado para controle dessa doença, até hoje presta assistência médica à população. A rede pública de assistência à saúde do município conta com seis Unidades Básicas de Saúde (UBS), que integram a Estratégia de Saúde da Família (ESF), um Centro de Saúde, uma unidade do Núcleo de Apoio à Saúde da Família (NASF), um hospital da Fundação Hospitalar do Estado de Minas Gerais (FHEMIG) e um hospital municipal. Inexistem instituições de longa permanência para idosos.

Para reconstruir o universo de representações (maneiras de pensar) e comportamentos (maneiras de agir) associados ao envelhecimento, foram selecionados idosos com 60 anos ou mais, residentes em Bambuí, cadastrados 
e assistidos pela ESF. Visando assegurar a multivocalidade dos participantes, o grupo de entrevistados incluiu pessoas de ambos os sexos, de diversas idades, variados níveis funcionais e residentes nas várias regiōes da cidade, e o critério de saturação regulou o tamanho da amostra (FONTANELLA et al., 2008). A identificação de aspectos operacionais de redundância e repetição de dados, fatores teóricos de consistência e representatividade de elementos associados ao envelhecimento, e a qualidade das informaçōes obtidas contribuíram para a decisão de um determinado ponto de saturação amostral.

O modelo de Signos, Significados e Ações (CORIN et al., 1992), utilizado na coleta e na análise dos dados, tem origem na corrente interpretativa da antropologia. Dela emerge a concepção geertziana da relação entre indivíduos e cultura, compreendida como um universo de símbolos e significados que permite aos sujeitos de um grupo interpretarem suas experiências e guiar suas ações (UCHÔA; VIDAL, 1994).

Para a coleta de dados, foi realizada entrevista semiestruturada no domicílio do entrevistado, possibilitando o acesso a lógicas conceituais privilegiadas por uma população específica para compreender e explicar uma determinada condição; bem como identificar os diferentes elementos de um contexto particular que intervêm na construção de comportamentos concretamente adotados por essa população diante do problema. Além disso, ela acede à sistematização dos elementos do contexto que participam da construção de maneiras típicas de pensar e agir dos participantes, no caso específico, como pensam e agem os idosos entrevistados diante do envelhecimento (UCHÔA; VIDAL, 1994). Todas as entrevistas foram gravadas após consentimento livre e esclarecido dos informantes.

Uma das grandes contribuições da antropologia para a saúde foi a construção de um quadro conceitual e metodológico que investiga o envelhecimento com base na perspectiva êmica, que dá "voz" ao interlocutor da pesquisa - a pessoa idosa - permitindo identificar e compreender como ele percebe esse processo (UCHÔA, 2003). Assim, na presente pesquisa, a pessoa idosa é convocada a falar sobre a vida e sobre si, mais especificamente sobre suas condições de saúde e doença, em seu ambiente local e cultural, lugar onde ela se organiza e que lhe confere significados particulares sobre a própria experiência.

Na concepção geertziana, a cultura é entendida como um texto interpretável que confere inteligibilidade às situaçôes e aos acontecimentos da vida, estruturando o 
campo social em um tecido semântico (GEERTZ, 1989). Dessa forma, os idosos constroem psicossocialmente sua experiência, como por exemplo, o processo de envelhecer, de adoecer e/ou de se tornar funcionalmente incapaz na velhice, em uma elaboração cultural de formas singulares de envelhecer.

Além disso, segundo Morin (2001), as sociedades só existem e as culturas só se formam, conservam, desenvolvem e transmitem através da interação entre os indivíduos e são organizadas e organizadoras por meio do veículo cognitivo da linguagem. Dispondo de seu capital cognitivo, cada cultura institui as normas que organizam a sociedade e governam os comportamentos individuais. A interação entre os indivíduos - portadores/transmissores da cultura - motiva novos conhecimentos que regeneram a sociedade, a qual, por sua vez, regenera a cultura. Assim, as normas culturais criam processos sociais e vivificam globalmente a complexidade social adquirida por essa mesma cultura, de tal modo que cultura e sociedade estão em relação formadora mútua (MORIN, 2001).

O saber biomédico, objeto da presente investigação, fundamenta-se na neutralidade e no paradigma positivista da ciência, alicerce conceitual da moderna medicina científica (RIOS et al., 2007). O modelo biomédico hegemônico na cultura ocidental tem como características ser:

- reducionista: reconhece apenas as causas orgânicas da doença (RIOS et al., 2007);

- generalizante: propóe-se a produzir modelos de validade universal e leis de aplicação geral, não se ocupando da singularidade dos indivíduos (CAMARGO JR., 2005);

- mecanicista: seus modelos tendem a naturalizar o corpo humano como uma gigantesca máquina, compreendido por uma causalidade linear e possível de ser traduzida em mecanismos (CAMARGO JR., 2005);

- analítico: a abordagem teórica e universal adotada para a elucidação das "leis gerais" sobre o funcionamento da "máquina humana" pressupóe o isolamento de partes e que o funcionamento do todo é dado pela soma das partes (CAMARGO JR., 2005).

Ao mesmo tempo, o modelo biomédico estimula o profissional médico a um comportamento cartesiano, que supóe o mundo de uma perspectiva objetiva externa a ele e a um distanciamento no relacionamento com o paciente, resultando na separação entre o observador e o objeto observado (BARROS, 2002). 
Gadamer (2006) percebeu tal cisão ao analisar as diferenças entre a visão biomédica e a visão dos idosos sobre a saúde, o que também foi evidenciado em um estudo que comparou o envelhecimento bem-sucedido medido pelos pesquisadores ao autorrelatado pelos próprios idosos.

Enquanto apenas $30 \%$ dos participantes foram objetivamente classificados como bem-sucedidos pelos pesquisadores, mais do que o dobro (63\%) dos idosos se declararam nessa condição (CERNIN; LYSACK; LICHTENBERG, 2011). Se nos estudos epidemiológicos e quantitativos os avaliadores valorizam atributos físicos e funcionais, os estudos qualitativos demonstram que os fatores psicológicos e sociais e a capacidade de adaptação às doenças influenciam mais a percepção que os idosos têm da própria saúde (VAHIA et al., 2010).

Sendo assim, é possível que, em havendo uma aproximação nas linguagens e na concepção dos saberes biomédico e popular, aconteça uma potencialização no cuidado, na adesão ao tratamento e até na melhoria da qualidade de vida das pessoas. $\mathrm{O}$ contrário pode ocorrer caso se observe uma dissociação entre a expectativa do sujeito e as normas biomédicas (CONRAD, 2007).

Assim, na abordagem antropológica hermenêutica utilizada neste estudo, o foco na doença como entidade biológica se desloca para a experiência da pessoa com a doença, em um determinado contexto social e cultural. Ressaltese que, em humanos, os fenômenos nunca são apenas um fenômeno, visto que estão sempre imbuídos de significado na junção entre os quadros pessoal e coletivo (CORIN, 1995). Esse significado é apropriado pelos pesquisadores da antropologia interpretativa como o elemento que influencia o curso da doença, moldando a experiência subjetiva, bem como o comportamento individual e social em resposta da doença (CORIN, 1995).

Desse referencial interpretativo da pesquisa qualitativa é possível proceder à distinção analítica entre a "doença processo" e a "doença experiência" como um elemento-chave de discussão (UCHÔA, 1997). A “doença processo” (disease) refere-se a anormalidades dos processos biológicos e/ou psicológicos, ao passo que a "doença experiência" (illness) refere-se à experiência psicossocial da doença. Para Cassell (1978), a expressão illness refere-se a "o que o paciente sente quando vai ao médico", e disease, a "o que ele tem quando sai do consultório médico e volta pra casa". Sendo, portanto, de grande importância compreender como a pessoa idosa percebe o cuidado médico em sua experiência no cotidiano da atenção à saúde. 
Foram entrevistados 57 idosos (27 homens e 30 mulheres), com idade que variava de 62 a 96 anos, residentes em Bambuí, cadastrados nas seis UBS e assistidos pela ESF. Quanto ao estado civil, 24 eram casados, um em união estável, sete solteiros, e 25 viúvos. A maioria deles teve filhos. No grupo, prevalecem a baixa escolaridade, forte predomínio da religião católica e a origem rural, sendo os principais motivos de mudança para a cidade a maior proximidade com o serviço de saúde e/ou com a escola para os filhos.

Todos os participantes responderam a questões referentes à sua percepção de saúde. $\mathrm{Na}$ análise das falas, não foi observada diferença entre a concepção de homens e mulheres sobre o tema estudado. Os achados da pesquisa demonstram como o conhecimento médico-científico, apropriado pela cultura local, influencia o modo de pensar e agir dos idosos de Bambuí. No campo de fala dos participantes, diversos significados e maneiras específicas de conceber o saber biomédico e a forma como esse saber define a velhice foram identificados na reprodução da fala de médicos; na referência a medicamentos e doenças; na suposta relação de causalidade entre patologias e hábitos de vida com as condiçôes de saúde e de existência; no relato de práticas concretas, como a utilização dos serviços de saúde e a realização de tratamentos, consultas, exames complementares, cirurgias, internações e outros procedimentos.

Após várias leituras e de um olhar específico e cuidadoso sobre as entrevistas, foram identificadas quatro categorias analíticas de significados associados ao saber biomédico: a valorização da biomedicina, a culpabilização dos indivíduos, a naturalização das doenças na velhice e os recursos e ações. Esses recortes foram julgados significativos, já que representam o sentido das ideias dos sujeitos pesquisados.

\section{A valorização da biomedicina}

Esta categoria confirma a literatura (GARCIA et al., 2005): o saber biomédico é muito valorizado pelos idosos bambuienses, especialmente na figura do médico, reconhecido como sua principal autoridade. Um idoso relata a sua confiança nesse profissional:

Tem um médico que é conhecido, então eu tenho aquela confiança de conversar com ele. Que nem eu falei pra ele: 'Eu quero consultar com o senhor. Eu quero, eu quero 
que o senhor, o senhor achar, o senhor me esclarecer, que eu acho que é bom saber o que que tá acontecendo ( $\mathrm{H} 7,84$ anos, casado).

No grupo estudado, a disciplina do "doente" à prescrição representa um valor, como pode ser comprovado por uma entrevistada que, ao ser indagada se toma a sua medicação corretamente, responde: "Tomo tudo direitinho. $\mathrm{O}$ médico até falou comigo 'coisa boa é tratar de quem quer melhorar" (M10, 72 anos, casada). É possível reconhecer a prática biomédica vigente e a normatização vertical, em que o médico aparece como detentor absoluto do conhecimento científico, e o paciente, como ser sem autonomia, examinado e compreendido de forma fragmentada (MOULIN, 2009). Além disso, o saber biomédico mostra-se moralizante ao determinar comportamentos e normas de conduta que regulam as ações do dia a dia dos entrevistados, ainda que:

a) não escutem o que a pessoa traz como demanda, conforme o relato de uma mulher muito idosa: “[...] a gente não precisa falar muita coisa que eles já tão dando a receita [...]” (M55, 86 anos, casada);

b) ignorem as experiências de vida pregressa, impondo-se de maneira autoritária, como explica esta senhora mais velha ao ser questionada se realiza visitas a outras pessoas: "Visita? Eu não saio de casa, não. À missa eu já não vou mais porque a gente tem, o médico mesmo fala: 'Não vai, não"” (M35, 93 anos, viúva);

c) contrariem a vontade dos sujeitos: "A minha glicose tá meio alta, sabe? Tenho que fazer umas dietas [...] É, agora é só deixar de comer um doce, né? Eu gosto de doce, mas a gente tem é que parar, né?” (H47, 69 anos, casado); e

d) o diagnóstico ou a prescrição sejam insatisfatórios, como mostra a fala de uma das entrevistadas: "Mas os médico é bom, boba, porque a doença mesmo é que não sai" (M24, 86 anos, viúva).

Além disso, em Bambuí, ao médico é conferida tamanha autoridade que, na fala de um idoso, ele chega a tutelar quem o consulta: “[...] um dia ele disse: 'N., eu vou internar você lá no sanatório.' Mas por que, doutor? 'Porque você não tem quem te olhe e lá você vai ter tudo, e eu sou médico de lá e eu te dou uma olhada diária"' (H3, 75 anos, casado). 
Nessa perspectiva, o saber biomédico assume um lugar social na sociedade em que institui um campo marcado por relaçôes de poder (SARTI, 2010), a imagem do profissional médico é preservada, e sua conduta, inquestionável. Ademais, como a argumentação de natureza biológica é apresentada com linguagem e técnicas complicadas, esse saber se apresenta como grande detentor do conhecimento sobre os processos da vida e sobre o sofrimento e o adoecimento (GAUDENZI; ORTEGA, 2012; ILLICH, 1975), sendo a doença incorporada à subjetividade da pessoa idosa para justificar a sua condição.

Na percepção de saúde dos entrevistados, é possível reconhecer uma crescente dependência e submissão ao conhecimento técnico-científico do médico, bem como a perda da autonomia dos indivíduos no cuidado à própria saúde, conforme explica uma senhora: "Ah, a minha saúde; eu quando faço um exame me fala que eu não sinto nada...” (M44, 69 anos, separada). Ademais, o desenvolvimento e o domínio da tecnologia pelo saber biomédico reforçam o triunfalismo da medicina no século XX: até mesmo a subjetividade e a experiência corporal ficam submissas ao veredicto dos exames complementares, as "provas concretas" da veracidade de seus argumentos, importantes instrumentos de convencimento, que reforçam a "ilusão compartilhada", implícita na demanda do paciente e na resposta do médico de que a medicina tudo pode (LE BRETON, 2011).

Portanto, tal categoria remete a vários elementos da crítica de Illich (1975) à medicina moderna, relativos aos malefícios provocados pelo processo de medicalização, em que esse autor introduz os conceitos de iatrogênese - iatros (médico) e genesis (origem) - social e cultural. A iatrogênese social diz respeito ao processo de dependência crescente da população, no caso presente da parcela idosa, em relação a prescrições médicas, medicações, exames laboratoriais, conhecimento especializado e normas de conduta da medicina, levando à disseminação da ideia do "papel de doente", em que o sujeito se torna passivo e dependente da autoridade médica.

A iatrogênese cultural, por considerar que a medicina desacredita e combate todas as outras formas de lidar com as doenças que não sejam comprovadas pela ciência, provoca uma destruição do potencial cultural das pessoas e das comunidades para lidar de forma autônoma com a enfermidade e o sofrimento (GAUDENZI; ORTEGA, 2012; NOGUEIRA, 2003). 


\section{A culpabilização do indivíduo}

Nesta categoria, o indivíduo assume a responsabilidade pela própria condição de saúde, na ideia de doenças autoinflingidas, resultantes de abusos corporais como a bebida, o fumo, a falta de exercícios (DEBERT, 1999). Em Bambuí, um idoso confirma que, para ter boa longevidade, "[...] o conselho que eu poderia dar é assim ó: primeiro: não beber, não usar drogas, não fumar e atividade". (H18, 65 anos, casado). Outro homem encontra na vida laboral a justificativa para sua condição de saúde na velhice, mas assume a culpa e responsabiliza a própria ignorância pelo comportamento de risco: "Eu fiquei nas condições que eu tô aqui, agora, por ignorância minha mesmo. No tempo que eu era novo, tinha saúde, graças a Deus, o peso que era pra dois eu queria pegar sozinho e muitas das vezes eu peguei" (H7, 84 anos, casado).

Nas entrevistas, o saber biomédico atribui a condição de saúde na velhice aos hábitos decorrentes do "estilo de vida" adotado ao longo de décadas, levando à ideia de que se trataria de uma escolha deliberada do indivíduo, o que, de certo modo, o culpa pela condição atual. Assim, na abordagem de problemas de ordem socioeconômico-cultural, a racionalidade médica desvia o foco do problema objetivo para aspectos subjetivos do indivíduo (CRAWFORD, 1977). Esses relatos, porém, calcados na vida, no trabalho braçal e na impotência dos idosos diante da situação, divergem frontalmente do formato previsível e controlado da vida, proposto pelo modelo biomédico, o qual parece ignorar que o "estilo de vida" do sujeito, muitas vezes, é o único modo possível de sobrevivência dentro de determinado contexto social (CASTIEL, 2003). Os entrevistados demonstram ter assimilado diretrizes do envelhecimento ativo como referência e se culpam por não corresponderem ao padrão esperado. Contudo, a velhice não é ressignificada como uma etapa valiosa da vida, construída em um contexto sociocultural, no qual o valor da pessoa independe da idade, da sua condição de saúde ou de qualquer outro atributo.

Os signos, os significados e as ações presentes na fala dos entrevistados apontam a necessidade de ampliar os determinantes da condição de vida na velhice para incluir fatores intrínsecos, situacionais, de história de vida e macroestruturais, em que a noção de boa longevidade como uma questão de responsabilidade individual exime as instituições sociais de seus deveres para com os idosos (NÉRI, 2005). Para Néri (2005), uma velhice saudável depende 
dos investimentos em saúde e em educação ao longo de toda a vida, cabendo ao governo, à escola e às profissões estabelecer as bases para um desenvolvimento bem-sucedido para todos os cidadãos.

Apesar disso, no grupo pesquisado, a ideia de velhice como encargo individual encontra-se a tal ponto culturalmente assimilada que outra senhora, em seu relato, chega a anistiar até mesmo Deus de qualquer responsabilidade: "O médico fala que eu constipei os ossos. Ah, gente [...] não é Deus que faz isso, não. Deus não faz nada ruim pra gente [...] Ah, eu acho que eu mesma sou culpada [...] Ah, porque eu trabalhava direto. Eu trabalhei 11 anos sem falhar um dia" (M8, 83 anos, viúva).

\section{A naturalização das doenças na velhice}

$\mathrm{Na}$ fala dos entrevistados, não se concebe a velhice sem doenças e sem a perda da saúde, como demonstra esta mulher idosa: "Já fiz muitos exames, já fiz três raios-X, não acusa nada e nem vai acusar que isso é velhice [risos]. [...] Gente, as mulher tão ficando tudo velha! 'Tô com isso, tô com aquilo'. Gente, isso é velhice! 'Que doença que é a da sua mãe'? É velhice!” (M19, 83 anos, viúva). Essa associação velhice-doença é tão forte que, se tiver boa saúde e boa capacidade funcional, uma pessoa não é considerada velha, conforme narra esta senhora, viúva pela segunda vez:

Eu acho que não tem idade pra falar aquela pessoa tá velha, não. Ela tendo saúde, ela não pensa que tá velha, não. Por exemplo, se ela sentir bem, se ela come bem, se ela dorme bem, se ela anda, se ela conversa com todo mundo, ela tá disposta pra tudo [...] Agora assim, eu acho que a pessoa tendo essa disposição, não [tem] velhice, não. Não tem velhice, que eu casei com o meu segundo marido, ele já tava com sessenta e muitos anos também. Nós viveu 18 anos. Ele morreu com 88 anos. Ele nunca foi assim, de ficar cabisbaixo e morreu. Adoeceu e num instantinho morreu. [Morreu sem ficar velho?] Morreu sem ficar velho [...] (M5, 77 anos, viúva).

Um homem idoso explica, de forma ainda mais contundente: "Só o que não tá bom é a velhice. Porque a velhice é doentia. Há um ditado que fala assim: senectus esculopus: a velhice é doentia. E é" (H15, 79 anos, casado). Referindo-se ao breviário latino ipsa senectus morbus, que quer dizer "a marca da velhice é a doença", sentido que foi registrado por Sêneca como senectus insanabilis morbus est e cuja tradução seria "a velhice é uma doença incurável" ou, como imortalizado por Terêncio, senectus ipsa morbus est, isto é, "a velhice é ela mesma uma doença”. 
Assim, a cultura ocidental repercute essa visão milenar da velhice, a qual representa a experiência do envelhecimento como inexorável tragédia pessoal, irreversível e irremediável. Nessa perspectiva dialética, a experiência corporal do idoso se transforma em uma experiência social, sendo reforçada pela ciência biológica, que define a velhice como uma degeneração orgânica irreversível e irremediável, fadada ao declínio das funções e das reservas fisiológicas e à morte (D'ALENCAR, 2012).

Um estudo realizado na cidade de Campinas (GARCIA et al., 2005) observou que os idosos daquela cidade têm a concepção de velhice como perda ou incapacidade, sendo as enfermidades consideradas distúrbios próprios da idade e sem tratamento. Uchôa et al. (2011), em Bambuí, demonstram que o olhar da comunidade também é carregado desse negativismo que o profissional expressa, corroborando o processo de naturalização e homogeneização da velhice, que simultaneamente mantém e reforça os estereótipos transmitidos pela cultura ocidental.

Um senhor explica a razão de sua dor, assumindo diagnósticos etiológicos, clínicos e radiológicos: "É coluna. Eu tenho artrose, bico-de-papagaio e desgaste. Tem três coisas, só pela idade, né? Tá doendo por causa já é mais minha idade" (H47, 69 anos, casado). Para Minayo, "um dos mitos mais populares sobre o envelhecimento é igualá-lo a uma doença” (MINAYO, 2011, p. 11). Confirmando-o, nota-se, nessa fala, a aceitação de sintomas e doenças, bem como da maior vulnerabilidade orgânica (ARAÚJO; SÁ; AMARAL, 2011).

Um idoso reproduz a fala do seu médico: "[...] [o médico] só falou comigo assim: 'O senhor não preocupa muito não, caça um jeito de ficar mais despreocupado, repouso, isso maior que você sente agora é idade. Essa idade da gente aparece uma coisinha aqui, aparece outra por lá, o senhor não tem que preocupar, não." (H7, 84 anos, casado). Essa recomendação médica de inatividade e repouso, porém, tende a agravar as doenças e a incapacidade, acelerar o processo de envelhecimento e gerar sentimentos de inferioridade e desgosto (SANTOS, 2002), retroalimentando um ciclo vicioso fundado em crenças e comportamentos que adoecem a velhice. Importante observar que o saber biomédico produz o argumento científico da senilidade - conceito que nomeia o envelhecimento patológico, ou seja, envelhecer com doenças -, conforme notado nas orientações do profissional médico, internalizadas pelo idoso e pela 
cultura local, nas quais as doenças são percebidas como consequências naturais e inerentes à idade avançada.

Por sua vez, a impotência do profissional médico em lidar com deficiências crônicas que requerem cuidados permanentes e o fato de esse profissional ser treinado para interceder em casos agudos talvez expliquem a fala deste entrevistado: "Vou ao médico diário, sô, meu Doutor é o ' $\mathrm{X}$ ', né? ' $\mathrm{X}$ ' que é médico meu, aí dá aquela perrengada ele arranja aquele remédio e fala: 'Cê leva esse e vai tomando, acaba uma receita e pega outra e, na hora que piorar mais, cê volta" (H23, 82 anos, casado - grifo nosso)

Percebem-se códigos da cultura que configuram o saber biomédico e se sustentam na relação com o saber popular. Todavia, o saber biomédico, tacitamente aceito pelos idosos, não propõe alternativas à velhice-doença, conforme ilustra a fala deste homem: "É meio sem recurso, porque a coluna não sara; cuidando a tempo, conserva; conforme a vez que dá, melhora; mas sarar, não sara, não [...] Agora é convencer como que tá, repouso, ficar quietinho e usar os remedinhos. É isso aî" (H7, 84 anos, casado).

Essa compreensão da velhice como tempo que exige resignação e desistência diante de perdas inexoráveis atribuídas à idade é compartilhada na percepção dos idosos entrevistados e na fala dos médicos que consultaram. Ela reforça na pessoa idosa a expectativa de perda gradual da capacidade vital e o medo da dependência, da incapacidade, dos enfrentamentos decorrentes de doenças, em especial das crônico-degenerativas, e da própria morte (SOUZA; ZAGONEL; MAFTUM, 2007). Nas falas, o temor da dependência chega a ser maior do que o de morrer, como explica este entrevistado:

Eu não tenho medo da morte não, se falar assim: vai morrer amanhã, não tem problema. Eu tenho medo é de, por exemplo, eu sou assim, um pouco agitado, se eu cair numa cama e não puder andar, um trem assim, aí eu tenho medo, de ficar dando trabalho pros outros, ficar pela mão dos outros. Aí é preferível que a gente morresse [risos] (H18, 65 anos, casado).

No depoimento dos idosos, o determinismo biológico da medicina, que associa a velhice a doenças; seu caráter mecanicista, que compara o corpo a uma máquina, e generalizante, que trata a velhice como um fato homogêneo e olha para os idosos como se todos fossem iguais (MINAYO, 2011), são reproduzidos por profissionais de saúde, incorporados pela cultura local e internalizados pelos participantes da pesquisa. Vale lembrar que, para além da formação técnico- 
científica que recebem, os profissionais de saúde integram a mesma sociedade e são portadores/transmissores da mesma cultura que a população idosa representada no estudo. Tudo isso contribui para a sedimentação do estereótipo de que a velhice é naturalmente doentia, e, por ser o envelhecimento um processo inexorável, progressivo e irreversível, não há muito que fazer a não ser esperar ("fazer repouso", "ficar quietinho").

Nesse contexto, estar idoso representa inevitavelmente assumir sua impotência e o temor diante da possibilidade de uma dependência futura, ao mesmo tempo em que negar a velhice se transforma no único meio possível de continuar a ser socialmente aceito.

\section{Os recursos e as ações}

O quarto tema trata dos recursos e das ações resulta da interação entre as três categorias anteriores: a valorização da biomedicina - a medicalização da vida; a culpabilização do indivíduo pela sua condição de saúde na velhice e a naturalização das doenças e limitações justificadas pela idade, que repercutem no pensamento e nas atitudes dos idosos e da sociedade.

Uma das maneiras de agir é a aceitação daquilo que é preconizado pelo saber biomédico para lidar com doenças crônicas e incuráveis, como relata esta senhora ao reconhecer como benéficos a consulta a especialista e o uso contínuo de medicamentos para tratar diferentes problemas de saúde:

Eu tenho Chagas, eu tenho é... essa tremura, Parkinson... Eu trato com um neurologista de [uma cidade próxima]. Ele falou pra mim: 'Ó, dona M., não tem cura, mas tem melhora, melhora. Se a senhora tomar os remedinhos direito e todos os remédios que eu tô receitando a senhora vai melhorando.' Na verdade, eu tô melhorando, alivia demais (M51, 70 anos, viúva).

Contudo, outra idosa, ao explicar por que não faz caminhadas, mostra que a experiência pessoal pode falar mais alto e desafiar os decretos da medicina:

Eu não ando mais, eu andava, fazia caminhada, depois que a D. morreu eu falei assim: Eu velha, tô aguentando os trancos e os barrancos tudo, passa apertado e tô passando e menina novinha morreu, eu não vou ficar fazendo caminhada, não! [Por quê? Ela morreu como?] De aneurisma fulminante. Morreu na hora. Aí eu larguei de fazer caminhada (M5, 77 anos, viúva).

Outro senhor, para ignorar esse prognóstico fatal que admite como natural a presença de enfermidades e de limitações na idade avançada, utiliza como 
estratégia não consultar o médico para não se deparar com os problemas inevitáveis da velhice:

Eu fico assim, eu sou uma pessoa diferente, eu não fico procurando. É igual você pegar um carro, um carro velho. Se você for com ele pro mecânico todo dia, você acha defeito pra ele todo dia, você entendeu. Aí você vai convivendo com um barulhinho, você vai lá, um barulhinho... Você vai convivendo. Porque, se você começar levar ele pro mecânico num primeiro barulhinho, aquilo lá às vezes tá tudo bão, você pensa assim: tem um barulhinho aí. Tira esse barulhinho e aparece um outro barulhinho (H18, 65 anos, casado).

Apesar disso, percebe-se internalizado o pensamento cartesiano e mecanicista fundante do saber biomédico, que compreende a velhice como uma equação matemática, na qual o "corpo velho = máquina defeituosa", ou seja, o sintoma representa o defeito que o idoso nomeia como "barulhinho". Ao fazê-lo, porém, propaga a concepção do corpo velho como uma máquina desgastada na qual defeitos/doenças são naturais e esperados, mas, para os quais, a "oficina" da ciência biomédica não oferece "conserto", reforçando uma vez mais a compreensão de que "a velhice é doentia por si só".

Portanto, dada a complexidade de interações que envolvem o conhecimento humano, embora permaneça incontestável, os entrevistados podem divergir ou resistir ao saber biomédico em seus modos de pensar e agir em relação às práticas de saúde e ao controle de doenças. Mas, diante da falta de alternativas para lidar com tal situação, um homem idoso defende que o recurso é pelejar e aprender a conviver com a dor e as doenças:

\footnotetext{
Então, a gente tem que aprender a viver com as doenças. Então, pelo longo, pelo longo tempo que eu venho sobrevivendo com essa doença, venho pelejando [...] Eu sinto muita dor na coluna cervical, isso embaixo da coluna. A única parte minha que eu não sinto dor ainda é nas mãos. Nos ombros, perna, lombo, eu não dou conta nem de levar a mão na cabeça. Aí eu vou suportando, aí vou levando uma vida razoável... (H43, 62 anos, união estável).
}

Talvez ele avalie a condição atual como razoável a partir da vivência de toda a vida, na qual sobreviver às condições de vida já representasse a prova máxima da sua resistência. O jeito é apelar para a razão para aprender a conviver com ela e seguir "pelejando", sem ousar questionar o que seria para uma pessoa idosa uma vida razoável. Pois, em uma perspectiva curativa, o saber biomédico não apresenta soluções para os problemas crônicos de saúde e suas mazelas, categorizando a velhice como uma doença incurável. 
Assim, na fala e nas prescrições dos profissionais médicos reproduzidas pelos idosos, prevalecem o discurso e a prática fatalistas de profissionais que se limitam a recomendar repouso (com o intuito de "poupar a máquina”), paciência e resignação diante de uma vida dolorosa e "razoável", demonstrando seu despreparo e impotência em frases do tipo "isso é coisa da idade" ou "na hora que piorar mais, cê volta” ou ainda proibindo os idosos de saírem de casa até para ir à missa, por exemplo. Esse modelo de assistência revelado no depoimento dos entrevistados falha na integralidade, na equidade e na humanização do cuidado, além de negar a finitude e a fragilidade humanas.

Desse modo, para lidar com problemas insolúveis que confrontam o limite da vida humana e a falta de alternativas do saber médico, a fé aparece como estratégia de enfrentamento, pela qual a religiosidade explica a vida, atribuindo significados aos fatos (ARAÚJO et al., 2008), oferecendo-lhe contornos de sentido que confortam os sujeitos. No campo de fala dos idosos entrevistados, suas crenças e tradições religiosas ajudam a explicar e a enfrentar o sofrimento experimentado por eles, como demonstra esta viúva ao ser questionada sobre o que poderia fazer para melhorar a saúde: "Ah, isso aí é só Deus! [Só Deus?] Só Deus, mais nada! Sem Deus não é mais nada!” (M4, 81 anos, viúva).

A religiosidade é um quadro de referência pessoal importante na idade avançada (SANTOS et al., 2013) e no grupo pesquisado, em que os comportamentos religiosos estão presentes na sua maneira de pensar a vida e experimentar o cotidiano, evidenciados na cultura pelos signos que sustentam coletivamente o discurso religioso. Especialmente nessa comunidade com forte influência católica, a religiosidade guarda um tom de fatalismo diante da situação insolúvel (GIACOMIN; UCHÔA; LIMA-COSTA, 2005), revelado na passividade e em ações de conformismo que também tendem a naturalizar o processo de envelhecimento com a incapacidade. A síntese dessa compreensão estaria na já citada anistia ao divino, pois Deus "não tem culpa" da condição em que vivenciam a velhice.

Uma das limitações do estudo é não investigar o saber biomédico a partir de profissionais de saúde. Interessava-nos, no entanto, compreender como o entrevistado interpretou tal saber e quais elementos ajudaram-no a compor sua visão sobre o envelhecimento. 


\section{Considerações finais}

No presente estudo, o saber biomédico influi nas práticas objetivas de saúde, mas também na subjetividade das pessoas em relação ao corpo e à vida. Nas alocuções, as pessoas idosas reproduzem a naturalização das doenças, culpabilizam-se pela condição atual, não aprendem - nem lhe são prescritas - outras maneiras de cuidar de si. Os signos identificados nas orientaçōes recebidas são: "aguardar", "aquietar-se", "pelejar", sem procurar falhas nessa "máquina velha".

De acordo com os significados retratados pelos entrevistados, o saber biomédico percebido é iatrogênico: medicaliza, mas não cuida; prescreve, mas não conforta; culpabiliza, mas não ajuda, além de reforçar a passividade, o conformismo, a incapacidade e o temor da dependência. Quanto às ações assumidas, os idosos são aconselhados a, "na hora que piorar mais", voltar ao médico para apanhar outra receita, com a vantagem de não "precisar falar muita coisa", para ir "levando uma vida razoável”; mesmo com "dor no lombo", "na coluna cervical" e com "bico de papagaio".

No presente contexto de envelhecimento populacional intenso, apesar de toda a racionalidade e potência apregoadas pelo saber biomédico, fica patente sua impotência face a face com a velhice, com a incapacidade e com a morte, bem como a urgência de levar esses temas para o cotidiano das equipes de saúde, das UBS e dos hospitais, das escolas técnicas, das faculdades e das universidades. Afinal, apesar de todo o poder tecnológico e das descobertas genéticas, moleculares e até atômicas, a pessoa idosa se mantém fiel à condição humana de finitude e de imperfeição. ${ }^{1}$

\section{Referências}

ARAÚJO, L.; SÁ, E. C. N.; AMARAL, E. B. Corpo e velhice: Um estudo das representações sociais entre homens idosos. Psicologia: Ciência e Profissão, v. 31, n. 3, p. 468-81, 2011.

ARAÚJO, M. F. M. et al. O papel da religiosidade na promoção da saúde do idoso. RBPS, v. 21, n. 3, p. 201-8, 2008.

BARROS, J. A. C. Pensando o processo saúde doença: A que responde o modelo biomédico? Saúde e Sociedade, v. 11, n. 1, p. 67-84, 2002.

CAMARGO JR, K. R. A Biomedicina. PHYSIS: Rev. Saúde Coletiva, v. 15 (Suplemento), p. $177-201,2005$. 
CASSELL, E. J. The Healer's Art: A new approach to the doctor-patient relationship. Harmondsworth: Penguin Books, 1978.

CASTIEL, L. D. Quem vive mais morre menos? Estilo de riscos e promoção de saúde. In: BAGRICHEVSKY, M.; PALMA, A.; ESTEVÃO, A. (Orgs.). A saúde em debate na educação física. Blumenau: Edibes, 2003. p. 79-98.

CERNIN, P. A.; LYSACK, C.; LICHTENBERG, P. A. A comparison of self-rated and objectively measured successful aging constructs in an urban sample of African American older adults. Clinical Gerontologist, v. 34, n. 2, p. 89-102, 2011.

CONRAD, P. The medicalization of society: on the transformation of human conditions into treatable disorders. Baltimore: The Johns Hopkins University Press, 2007.

CORIN, E. The culture frame: Context and meaning in the construction of health. In: AMICK, B.C. et al. Society and Health. Oxford: Oxford University Press, 1995. p. 272-304. Disponível em: <http://books.google.com.br/books?hl=pt-R\&lr=\&id=J3Uer_Iv0V8C\&o $\mathrm{i}=$ fnd $\& p g=$ PA $272 \& \mathrm{dq}=\mathrm{CORIN},+\mathrm{E} .,+1995 .+$ The + culture + frame $:+$ Context + and $\&$ ots $=\mathrm{u}$ IbVwR8suM\&sig=E5N9jGmjyE8eVFW_5rpr76AE79E\#v=onepage\&q\&f=true $>$. Acesso em: 10 jan. 2013.

CORIN, E. et al. Articulation et variations des systèmes de signes, de sens et d'actions. Psychopathologie Africaine, v. 24, p. 183-204, 1992.

CRAWFORD, R. You are dangerous to your health: The ideology and politics of victim blaming. Int. J. Health Serv., v. 7, n. 4, p. 663-80, 1977.

D'ALENCAR, R. S. (Res)significando a solidariedade na velhice: Para além de laços consanguineos. Acta Scientiarum. Human and Social Sciences (Maringá), v. 34, n. 1, p. 9-17, 2012.

DEBERT, G. G. A reinvenção da velhice: Socialização e processos de reprivatização do envelhecimento. São Paulo: Edusp/FAPESP, 1999.

FONTANELLA, B. J. B.; RICAS, J.; TURATO, E. R. Amostragem por saturação em pesquisas qualitativas em saúde: Contribuições teóricas. Cad. Saúde Pública, v. 24, n. 1, p. 17-27, 2008.

GADAMER, H. G. O caráter oculto da saúde. Petrópolis: Vozes, 2006.

GARCIA, M. A. A. et al. Idosos em cena: Falas do adoecer. Interface (Botucatu), v. 9, n. 18, p. 537-52, set./dez. 2005.

GAUDENZI, P.; ORTEGA, F. O estatuto da medicalização e as interpretações de Ivan Illich e Michel Foucault como ferramentas conceituais para o estudo da desmedicalização. Interface (Botucatu), v. 16, n. 40, p. 21-34, 2012.

GEERTZ, C. A interpretação das culturas. Rio de Janeiro: Livros Técnicos e Científicos Editora, 1989. 
GIACOMIN, K. C.; UCHÔA, E.; LIMA-COSTA, M. F. F. Projeto Bambuí: A experiência do cuidado domiciliário por esposas de idosos dependentes. Cad. Saúde Pública, v. 21, n. 5 , p. 1509-18, 2005.

ILLICH I. A expropriação da saúde: Nêmesis da Medicina. Rio de Janeiro: Nova Fronteira, 1975.

INSTITUTO BRASILEIRO DE GEOGRAFIA E ESTATÍSTICA. Dados gerais e informaçôes estatísticas da cidade de Bambuí. Disponível em: <http://www.ibge.gov.br/cidadesat/xtras/ perfil.php? codmun=310510\&search=minas-gerais|bambui >. Acesso em: 15 ago. 2013 .

- Observações sobre a evolução da mortalidade no Brasil: o passado, o presente e perspectivas. Rio de Janeiro, 2010. Disponível em: <http://www.ibge.gov.br/home/ estatistica/populacao/tabuadevida/2009/notastecnicas.pdf>. Acesso em: 27 dez. 2012.

LE BRETON, D. Antropologia do corpo e modernidade. Petrópolis: Vozes, 2011.

MINAYO, M. C. S. Envelhecimento demográfico e lugar do idoso no ciclo da vida brasileira. In: TRENCH, B.; ROSA, T. E. C. (Orgs.). Nós e o outro: envelhecimento, reflexões, práticas e pesquisa. São Paulo: Instituto de Saúde, 2011. p. 7-15. Disponível em: <http://bases.bireme. $\mathrm{br} / \mathrm{cgi}$-bin/wxislind.exe/iah/online/?IsisScript=iah/iah.xis \&src=google \&base =LILACS \&la ng=p\&nextAction =lnk\&exprSearch=653335\&indexSearch=ID>. Acesso em: 10 dez. 2012 . MORIN, E. O método. 4. As ideias. 2. ed. Porto Alegre: Sulinas, 2001.

MOUlin, A. M. O corpo diante da medicina. In: CORBIN A.; COURTINE J. J.; VIGARELLO G. História do corpo: as mutações do olhar: O século XX. 3. ed. Petrópolis: Vozes, 2009. p. 15-82.

NERI, A. L. As políticas de atendimento aos direitos da pessoa idosa expressas no Estatuto do Idoso. A Terceira Idade (SESC), v. 16, n. 34, p. 7-24, 2005.

NOGUEIRA, R. P. A segunda crítica social da saúde de Ivan Illich. Interface (Botucatu), v. 7, n. 12, p. 185-90, fev. 2003.

RIOS, D. F. F. et al. O programa Bolsa-Família em um contexto de cidades rurais: O caso de Bambuí, MG. Oikos Viçosa (Viçosa), v. 22, n. 2, p. 150-70, 2011.

RIOS, E. R. G. et al. Senso comum, ciência e filosofia - elo dos saberes necessários à promoção da saúde. Cien. Saude Colet., v. 12, n. 2, p. 501-09, 2007.

SANTOS, G. A. Os conceitos de saúde e doença na representação social da velhice. Revista Virtual Textos e Contextos, v. 1, n. 1, p. 1-12, 2002.

SANTOS, W. J. et al. Enfrentamento da incapacidade funcional por idosos por meio de crenças religiosas. Cien. Saude Colet., v. 18, n. 8, p. 2319-28, 2013.

SARTI, C. Corpo e doença no trânsito de saberes. Revista Brasileira de Ciências Sociais, v. 25, n. 74, p. 77-91, 2010. 
SOUZA, J. R.; ZAGONEL, I. P. S.; MAFTUM, M. A. O cuidado de enfermagem ao idoso: Uma reflexão segundo a teoria transcultural de Leininger. Revista RENE (Fortaleza), v. 8, n. 3, p. 117-125, set./dez. 2007.

TESSER, C. D.; LUZ, M. T. Uma introdução às contribuições da epistemologia contemporânea para a medicina. Cien. Saude Colet., v. 7, n. 2, p. 363-72, 2002.

TURATO, E. R. Métodos qualitativos e quantitativos na área da saúde: Definições e seus objetos de pesquisa. Rev. Saúde Públ., v. 39, n. 3, p. 507-14, 2005.

UCHÔA, E. et al. An anthropologic study on strategies for addressing health problems among the elderly in Bambuí, Minas Gerais State, Brazil. Cad. Saúde Pública, v. 27, supl. 3, p. s370-s377, 2011.

UCHÔA, E.; VIDAL, J. M. Antropologia Médica: Elementos conceituais e metodológicos para uma abordagem da saúde e da doença. Cad. Saúde Pública, v. 10, n. 4, p. 497-504, 1994.

UCHÔA, E. Contribuiçôes da antropologia para uma abordagem das questões relativas à saúde do idoso. Cad Saúde Pública, v. 19, n. 3, p. 849-53, 2003.

. Epidemiologia e Antropologia: Contribuições para uma abordagem dos aspectos transculturais da depressão. In: CANESQUI, A. M. (Org.). Ciências Sociais e Saúde. São Paulo: Hucitec-Abrasco, 1997. p. 87-109.

VAHIA, I. V. et al. Subthreshold depression and successful aging in older women. Am. J. Geriatr. Psychiatry, v. 18, n. 3, p. 212-20, 2010.

\section{Nota}

${ }^{1}$ G. V. O. Moraes participou da concepção e projeto; análise e interpretação dos dados e redação do artigo. K. C. Giacomin participou da concepção e projeto; revisão crítica relevante do conteúdo intelectual; aprovação final da versão a ser publicada. W. J. dos Santos participou da análise e interpretação dos dados. J. O. A. Firmo participou da concepção e projeto; revisão crítica relevante do conteúdo intelectual; aprovação final da versão a ser publicada. 
The perception of the elderly about the

biomedical knowledge in the care of old age and "things of old age"

The biomedical knowledge influences objective and subjective practices of people concerning body, health and life. Given the current context of population aging, this anthropological work aims to understand how the elements of biomedical knowledge influences the perception of the disease process and its relationship with aging among elderly community residents of Bambuí, Minas Gerais state, Brazil. The studied group comprised 57 older adults ( 27 men and 30 women) aged between 62 and 96 years. The model of signs, meanings and actions guided the collection and analysis of data, allowing the systematization of context elements that participate in the construction of typical ways of thinking and acting of the respondents in face of aging. The results show that the medical and scientific knowledge appropriated by the local culture affects the ways of thinking and acting of the elderly investigated, identified as analytical categories of meaning: the valuation of biomedicine, the blaming of individuals, the naturalization of diseases in old age and resources and actions used by the elderly. Participants reproduce the biomedical view that associated diseases and limitations of age, the elderly themselves responsible for the current health condition, and still recommends rest and resignation for old age and illness lived with disability.

> Key words: elderly; biomedical knowledge; aging; healthdisease process. 